\title{
Dopamine D2 Receptor Mechanisms Contribute to Age-Related Cognitive Decline: The Effects of Quinpirole on Memory and Motor Performance in Monkeys
}

\author{
A. F. T. Arnsten, ${ }^{1}$ J. X. Cai, ${ }^{2}$ J. C. Steere, ${ }^{1}$ and P. S. Goldman-Rakic ${ }^{1}$ \\ 'Section of Neurobiology, Yale Medical School, New Haven, Connecticut 06510-8001 and ${ }^{2}$ Kunming Institute Of \\ Zoology, Academia Sinica, Kunming, Yunnan, China 650223
}

The D2 dopamine (DA) receptor agonist, quinpirole, was characterized in young adult monkeys, young reserpinetreated monkeys and aged monkeys to assess the contribution of DA to age-related loss of prefrontal cortical (PFC) cognitive function. Monkeys were tested on a delayed response memory task that depends on the PFC, and a fine motor task that taps the functions of the motor cortex. In young adult monkeys, low quinpirole doses impaired performance of the PFC and fine motor tasks, while higher doses improved memory performance and induced dyskinesias and "hallucinatory-like" behaviors. The pattern of the quinpirole response in reserpine-treated monkeys suggested that the impairments in delayed response and fine motor performance resulted from drug actions at D2 autoreceptors, while the improvement in delayed response performance, dyskinesias and "hallucinatory-like" behaviors resulted from actions at postsynaptic receptors. In aged monkeys, low doses of quinpirole continued to impair fine motor performance, but lost their ability to impair delayed response performance. The magnitude of cognitive improvement and the incidence of "hallucinatory-like"' behaviors were also reduced in the aged animals, suggesting some loss of postsynaptic D2 receptor function. The pattern of results is consistent with the greater loss of DA from the PFC than from motor areas in aged monkey brain (Goldman-Rakic and Brown, 1981; Wenk et al., 1989), and indicates that DA depletion contributes significantly to agerelated cognitive decline.

[Key words: prefrontal cortex, motor cortex, memory hallucinations, dopamine D2 receptor, quinpirole, raclopride, SCH23390, reserpine, rhesus monkey, delayed response task, fine motor task, aging]

Research on the neural mechanisms underlying age-related cognitive decline continues to focus on acetylcholine, despite accumulating evidence that normal aging has little effect on cholinergic systems. For example, intensive studies of the monkey brain have shown that cholinergic markers show little (Wenk et

Received Apr. 11, 1994; revised Nov. 7, 1994; decepted Nov. 10, 1994.

This research was supported by PHS Grants AG06036 to A.F.T.A. and MH44866 to P.S.G.-R., and by the Scientific Foundation of the Academia Sinica, Grant K.P. 85 to J.X.C. We are grateful to Lisa Ciavarella, Tracy White, and Xiao Kun-Yan for their invaluable technical assistance.

Correspondence should be addressed to A. F. T. Arnsten, Section of NeuIobiology, Yale Medical School, 333 Cedar Street, New llaven, CT 065108001 .

Copyright (C) 1995 Society for Neuroscience $0270-6474 / 95 / 153429-11 \$ 05.00 / 0$ al., 1989) or no change with age (Wenk et al., 1991), and there are only minor differences in the number and size of cholinergic neurons (Stroessner-Johnson et al., 1992). Furthermore, careful and thorough lesions of the basal forebrain in young monkeys have only limited effects on cognitive function (Voytko et al., 1994). Thus, it is doubtful that degeneration of cholinergic neurons contributes substantially to age-related cognitive deficits.

In contrast to acetylcholine, biochemical studies have shown marked and consistent depletion of dopamine (DA) and its metabolites in the aged monkey brain. DA in the prefrontal cortex (PFC) is particularly vulnerable to the effects of age: DA in the PFC is depleted early in the aging process (e.g., 20+ years; Goldman-Rakic and Brown, 1981; Wenk et al., 1989), and PFC DA is almost undetectable in very old monkeys (e.g., 30+ years; Wenk et al., 1989). By comparison, the nearby motor cortex (Brodmann area 4; Goldman-Rakic and Brown, 1981) and striatum (Goldman-Rakic and Brown, 1981; Wenk et al., 1989) show less pronounced DA age-related depletion, indicating that various DA systems are differentially affected by the aging process.

Cognitive functions are also differentially influenced by advancing age: $\mathrm{PFC}$ cognitive deficits are evident early in the aging process, and become marked in advanced age (Bartus et al., 1978; Bartus, 1979; Walker et al., 1988; Rapp and Amaral, 1989; Bachevalicr ct al., 1991), while recognition memory (Rapp and Amaral, 1989) and motor skill learning (e.g., the Rosette task; Bachevalier et al., 1991) are less affected by the aging process. These parallels in neurochemical and behavioral changes suggest that DA loss may contribute to PFC age-related cognitive decline, particularly as DA is vital to proper PFC function (Brozoski et al., 1979). However, the functional relationship between DA loss and PFC cognitive deficits in aged individuals has rarely been examined (Luine et al., 1990; Arnsten et al., 1994).

The current study addressed this issue by assessing the functional integrity of the DA system in young versus aged monkeys using the D2 agonist, quinpirole. D2 agonists have both pre- and postsynaptic effects in brain, including the PFC: D2 autoreceptor stimulation inhibits DA release from terminals in the rodent $\mathrm{PFC}$ (Plantje et al., 1987), while stimulation of post-synaptic D2 receptors inhibits PFC cell firing (Thierry et al., 1986; Sesack and Bunney, 1989). Thus, D2 agonists can be used to probe the status of the presynaptic element (i.e., endogenous DA and autoreceptor function) as well as postsynaptic D2 function. The following research examined pre- versus postsynaptic effects of quinpirole on PFC and motor functions in young adult monkeys, aged monkeys with naturally occurring monoamine loss, and young monkeys experimentally depleted of monoamines using 
chronic reserpine treatment. The delayed response task was used to assess PFC function (Goldman-Rakic, 1987), while a fine motor task was used as a measure of the functional status of the motor cortex, a cortical region with a very dense DA projection in primates (Lewis et al., 1987; Williams and Goldman-Rakic, 1993). The results of this study indicate that loss of DA function in the PFC contributes substantially to age-related cognitive decline.

\section{Materials and Methods}

Subjects. Three groups of adult female rhesus monkeys (Macaca $m u$ latta) were used in this study: five young adult monkeys estimated as ranging between 4 and 9 years; eight aged monkeys ranging in age from about 20 to 40 years, and three young rhesus monkeys ranging in age between 8 and 15 years who were chronically treated with reserpinc. All animals were housed individually under standard laboratory conditions. The three reserpine-treated young monkeys were treated and rested at the Kunming Institute of Zoology in Kunming, China, under the supervision of Dr. Cai; the remaining animals were housed and tested at the Yale Medical School, New Haven, CT. Dr. Cai had previously trained at Yale Medical School with Drs. Arnsten and GoldmanRakic, thus ensuring comparable methods between the two institutions. As actual birth dates were unavailable for most monkeys, ages were estimated on the basis of prior breeding and behavioral testing records, dental records, and general appearance. Rhesus monkeys in captivity have been reported to live 20-25 years and occasionally longer (Lapin et al., 1979; Tigges et al., 1988).

Delayed response testing. Cognitive testing was conducted in a Wisconsin General Test Apparatus (WGTA) in a sound-attenuating room. Background masking noise (60 dB, wideband) was used to minimize auditory distractions. Animals were always tested at the same time of day immediately prior to feeding. Highly palatable food rewards (e.g., peanuts, raisins, or chocolate chips) were utilized during testing to minimize the need for dietary regulation. Using these conditions, no problems with motivation were evident.

The monkeys had been previously trained on the two-well delayed response task. During delayed response, the animal watches as the experimenter baits one of two food wells. The food wells are then covered with identical cardboard plaques, and an opaque screen is lowered between the animal and the test tray for a specified delay. At the end of this delay, the screen is raised and the animal is allowed to respond. Reward is quasirandomly distributed between the left and right wells over the 30 trials that make up a daily test session.

In order to observe the effects of drug on memory capacity, the animals were trained on a variable delayed response task in which the delays varied between less than $1 \mathrm{sec}$ " 0 " sec) and the temporal interval that produced performance near chance levels for each animal within a session. Five different delay lengths were quasi-randomly distributed over the 30 trials that made up a single test session. For example, the range of delays for young monkey \#442 was " 0 ," 35,70 , 105 , and $140 \mathrm{sec}$. All monkeys performed perfectly at " 0 " sec and exhibited increasing difficulty with progressively longer delays, a pattern consistent with memory impairment. Delays were adjusted until the animals showed stable baseline performance of approximately $83 \%$ correct for the 30 trials, thus leaving room for improvement or impairment in performance. The aged animals performed at a baseline level of only about $70 \%$ correct, even at lower delays (e.g. delays of " 0 ," 4 , 8,12 , and $16 \mathrm{sec}$ for the youngest aged monkey, 502), consistent with age-related deficits on this task. Chronic reserpine treatment also reduced the baseline performance of young monkeys to about $70 \%$ correct. The young and aged monkeys were tested twice a week, with 3$4 \mathrm{~d}$ separating test sessions (e.g., Mondays and Thursdays). The reserpine-treated monkeys were injected everyday with reserpine, and thus were tested on a daily basis.

Fine motor performance. Fine motor abilities were assessed in the WGTA by allowing the animals to retrieve small food rewards placed closely together on a modified pegboard. Successful retrieval of the rewards required precise grasping hetween the thumb and an opposing digit. Access time was limited to maximize an animal's speed of responding. The number of rewards retrieved in the allotted time (e.g., $30 \mathrm{sec}$ ) was used as an estimate of fine motor ability. All drug responses were compared to performance on vehicle (previous test session). Fine motor testing immediately followed delayed response testing for most animals. Two young monkeys were tested on the fine motor and delayed response tasks on separate days due to motivation problems when the tasks were administered in tandem. Only four of five young monkeys and five of eight aged monkeys were able to participate in this experiment due to missing digits or unstable performance.

Reserpine treatment significantly decreased fine motor performance from about 24 rewards retrieved/30 sec without reserpine to approximately $3.5 / 30 \mathrm{sec}$ following reserpine treatment. In order to diminish the bias of floor effects, the amount of time allotted to perform the task was increased to $30 \mathrm{~min}$ to restore the previous level of performance prior to challenge with quinpirole.

General behavioral observations. Changes in behavior were evaluated during cognitive testing and in the home cage by an experimenter who was familiar with the animal, but was "blind" to the drug treatment conditions. Sedation and agitation were rated using a nine point scale, where $0=$ normal level of arousal, $I=$ quieter than usual, $I I=$ sedated (drooping eyelids, slowed movements), III = intermittent sleeping, and IV = too sedated to finish testing; $-\mathrm{I}=$ more alert than usual, - II $=$ slight agitation, but not sufficient to disrupt testing, - III = agitation disrupting testing, and $-\mathrm{IV}=$ too agitated to test. Aggression was rated using a 7 point scale, where $0=$ normal level of aggression, $-I=$ slightly more aggressive, - II $=$ moderately more aggressive, and - III = extremely aggressive; $\mathrm{I}=$ slightly more docile, II = moderately more docile, and III = very docile.

The animals were also observed for: changes in gross motor function (e.g., circling), dyskinesias (including chewing, yawning, grimacing, exaggerated blinking, and ballistic movements of the arms), excessive grooming or scratching, oral behaviors including licking or gnawing (e.g., on cage bars), hyperreactivity to stimuli (assessed by the presence of a startle response to a small movement of a pencil), and general appearance (e.g., pallor). Unexpectedly, monkeys also exhibited "hallucinatory-like" behaviors, complex, coordinated behaviors which were directed at seemingly nonexistent stimuli. For example, animals would exhibit a series of focused eye movements, as if tracking a moving object, followed by a swatting movement directed at the center of their gaze. These behaviors resembled those produced by chronic high dose amphetamine treatment in monkeys (e.g., Nielsen et al. 1983). The experimenters only scored an episode of "hallucinatory-like" behavior if it was clear that no actual object was directing the animal's behavior. "Hallucinatory-like" behaviors were distinguished from dyskinesias and from simple scratching movements, which were also increased by high dose quinpirole administration. It is recognized that these behaviors are difficult to study in a rigorous manner; however, an attempt was made to describe these abnormal behaviors given their potential clinical significance. A more detailed characterization of this phenomenon is being conducted in an independent study.

Drug administration. Drug solutions were made fresh each day under aseptic conditions. Quinpirole, raclopride or SCH23390 were diluted in sterile saline. Drug or sterile saline vehicle was injected intramuscularly $1 \mathrm{hr}$ prior to delayed response testing. With the exception of reserpine (see below), all drug doses were acute. The quinpirole doses ranged from 0.000001 to $1.0 \mathrm{mg} / \mathrm{kg}$; the doses of antagonist needed to block the quinpirole response are described in the Results. Quinpirole doses were administered quasi-randomly with the one caveat that the initial dose was never greater than $0.1 \mathrm{mg} / \mathrm{kg}$ for health reasons. The health of the animals was also protected by not administering the highest doses to animals who exhibited significant distress (i.e., impaired performance due to marked hypotension, dyskinesias, etc.). On completing a dose/ response curve, selected doses that produced performance above baseline performance were repeated for replicability of the response. Responses that were replicable were then challenged with antagonist. The two experimenters testing or rating the animal were "blind" to the drug treatment conditions. Drug administration occurred only after an animal had returned to baseline performance for two consecutive test sessions. Therefore, all washout periods between drug injections were at least $10 \mathrm{~d}$.

Reserpine-treated young monkeys were injected once daily with 0.1 $\mathrm{mg} / \mathrm{kg}$ reserpine solution for at least $5 \mathrm{~d}$ prior to challenge with quinpirole. Previous research has shown that at least 3-4 days of daily reserpine injections are needed to produce stable deficits in delayed response performance (Cai et al., 1993). On the challenge day, reserpine+saline or reserpine+quinpirole were injected $1 \mathrm{hr}$ prior to delayed response testing. The dose of reserpine was $0.1 \mathrm{mg} / \mathrm{kg}$, the doses of quinpirole used in this experiment ranged from 0.00001 to $0.08 \mathrm{mg} / \mathrm{kg}$. 


\section{YOUNG MONKEYS}

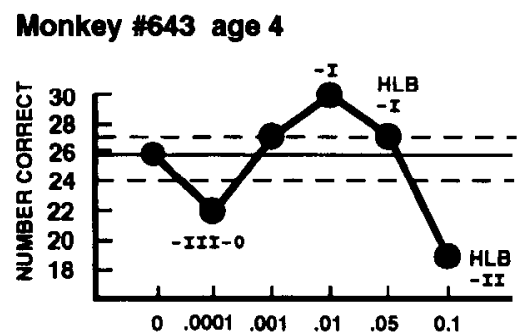

Monkey \#666 est. age 5

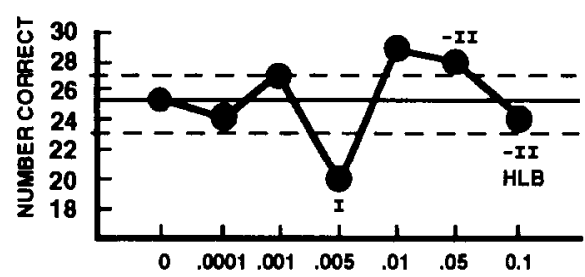

Monkey $\$ 613$ est. age 5

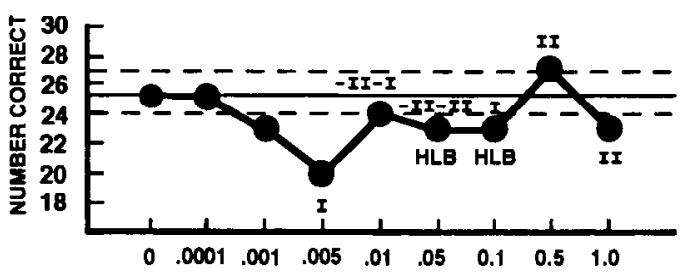

Monkey \#443 est. age 9

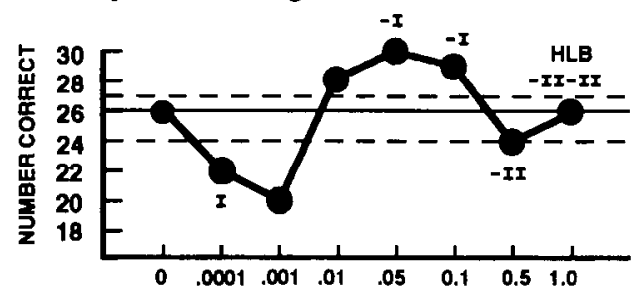

Monkey \#442 est. age 9

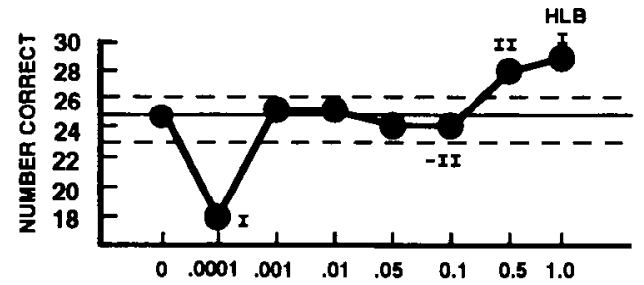

\section{DOSE OF QUINPIROLE (mg/kg)}

Figure 1. The effects of quinpirole on the delayed response performance of young, adult monkeys. Individual dose/response curves and estimated ages for the five monkeys who participated in this study are shown. The mean of matched saline $(0 \mathrm{mg} / \mathrm{kg})$ performance for each individual animal in this experiment is indicated by the horizontal line; the range of matched saline performance for each individual animal in this experiment is indicated by the dashed horizontal lines. Quinpirole
Quinpirole was kindly provided by Lilly Research Laboratories (Indianapolis, IN), raclopride by Dr. S. Ogren (Astra Pharmaceuticals, Sweden), haloperidol for injection by the R. W. Johnson Pharmaceutical Research Institule (Spring House, PA) and SCH23390 maleate by Schering Corp. (Bloomfield, NJ). Reserpine solution for injection $(1 \mathrm{mg} /$ $\mathrm{ml}$ ) is no longer obtainable in the United States but is still available in China. Injectable reserpine was generously supplied to Dr. Cai by the Qiaoguang Pharmaceutical Factory (Guangzhou City, Guangzhou Province, China).

Data analysis. Delayed response performance on drug was compared with matched vehicle (saline) control performance for the same week. Fine motor performance was also compared to matched vehicle control performance. Since the animals served as their own controls, statistical analyses employed repeated measures designs: paired $t$ test (also called dependent $t$ test or $t$-dep), and one- or two-way analyses of variance with repeated measures followed by post hoc tests (1-ANOVA-R on drug dose; or 2-ANOVA-R with factors of drug and delay). For young Inonkeys, the effect of dose of quinpirole was tested using a 1-ANOVA-R for doses $0,0.0001,0.001,0.01,0.05$, and $0.1 \mathrm{mg} / \mathrm{kg}$. Higher doses were not included in the analysis as they were not tolerated by one animal. For aged monkeys, the effect of quinpirole dose was tested using a 1-ANOVA-R for doses $0,0.0001,0.001$, and $0.01 \mathrm{mg} / \mathrm{kg}$, as the oldest animal could not tolerate doses higher than $0.01 \mathrm{mg} / \mathrm{kg}$. Comparisons between quinpirole + saline versus quinpirole + antagonist utilized paired $T$ tests, while comparisons between young and aged animals utilized unpaired $T$ tests (also called independent $T$ test or $t$-ind). Correlations between age and drug efficacy (largest effect of drug) utilized a nonparametric analysis, (Spearman test), due to the use of estimated ages. Differences in behavioral ratings between young and aged monkeys also used a nonparametric test (Mann-Whitney $U$ ). Statistical analysis was conducted on a Macintosh LC III computer using a statistics package (SYSTAT).

\section{Results}

Observations of quinpirole's effects on behavior

The effects of quinpirole on delayed response and fine motor performance occurred within a constellation of behavioral changes. In young adult monkeys, low doses of quinpirole frequently produced behavioral quieting, while higher doses produced a spectrum of behaviors including increased agitation, scratching/grooming, dyskinesias, sedation, pallor, hyper-reactivity to stimuli, and "hallucinatory-like" behaviors (Fig. 1). The potency of quinpirole in eliciting "hallucinatory-like" behaviors showed a relationship with age: "hallucinatory-like" behaviors were evident in the $0.05-0.1 \mathrm{mg} / \mathrm{kg}$ range in the three postadolescent animals $(666,613$, and 643), while the two animals estimated to be 9 years ( 442 and 443 ) required doses of $1.0 \mathrm{mg} /$ $\mathrm{kg}$ to induce these abnormal behaviors (Fig. 1). "Hallucinatorylike" behaviors were also less prominent in the aged monkeys; these behaviors were seen in five of five young monkeys but only four of eight aged animals (young vs aged: Mann-Whitney $U=30, p=0.068$; Figs. 1, 2). In contrast, aggression was more apparent in the aged group $(0.05 \mathrm{mg} / \mathrm{kg}$ quinpirole: median aggression scores of 0 for the young monkeys and - II for the aged monkeys: Mann-Whitney $U=0.0, p=0.007$ ).

Quinpirole had marked effects on the behavior of reserpinetreated monkeys. Quinpirole produced a significant, dose-related reduction of reserpine's sedative effects (Fig. 3A; Friedman statistic $=8.5, p=0.037$ ), suggesting that the quieting effects of low doses of quinpirole in young adult animals resulted from drug actions at DA autoreceptors. At higher doses, quinpirole frequently induced agitation, dyskinesias, and "hallucinatory-

$$
\leftarrow
$$

also induced changes in behavioral ratings. Sedation/agitation scores different from 0 are indicated; description of these scores is given in Materials and Methods. $H L B$ indicates that "hallucinatory-like" behaviors were observed at that dosage during cognitive testing. 


\section{AGED MONKEYS}

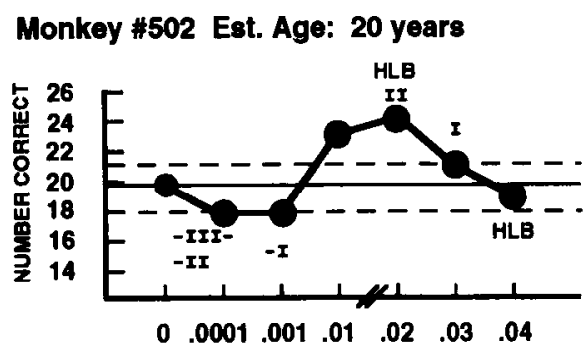

Monkey \#499 Est. Age: 20 years

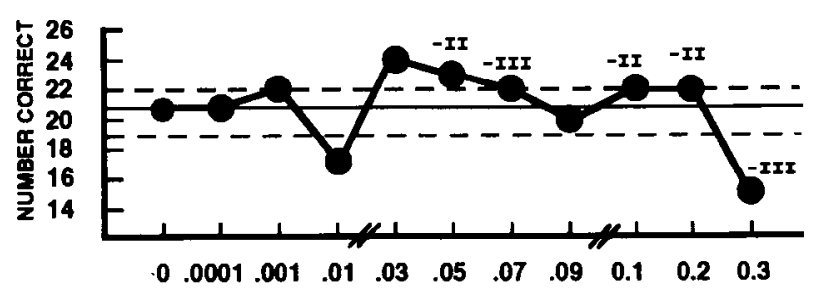

Monkey \#343 Est. Age: 33 years

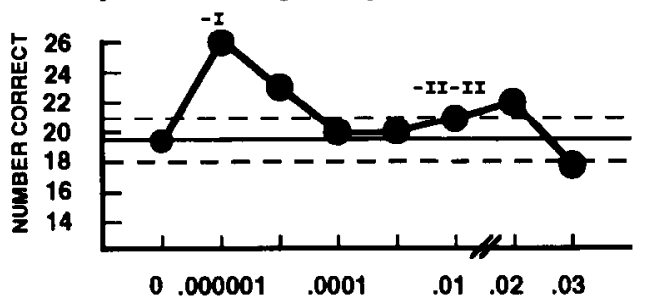

Monkey \#121 Est. Age: 38 years

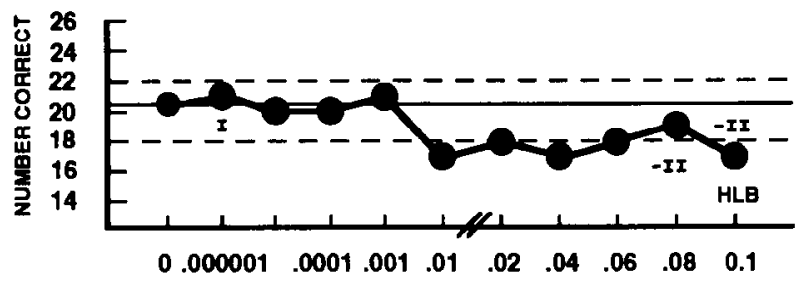

Monkey \#107 Est. Age: 40 years

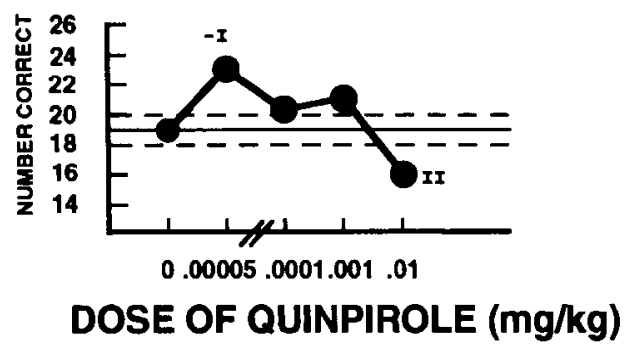

Figure 2. The effects of quinpirole on the delayed response performance of five representative aged monkeys (partial dose/response curves for the three remaining monkeys are shown in Fig. 8). With increasing age, the typical biphasic dose/response curve is lost and is replaced by monophasic improvement (e.g., monkey 343 ) or no effect (e.g., monkey 121). Results represent the number correct out of a possible 30 trials. The mean of matched saline $(0 \mathrm{mg} / \mathrm{kg})$ performance for like" behaviors (Fig. 3A), suggesting that these behavioral changes resulted from quinpirole actions at postsynaptic receptors.

\section{Quinpirole's effects on delayed response performance}

Young adult monkeys. Quinpirole significantly altered the delayed response performance of young adult monkeys [1-ANOVA-R: significant effect of quinpirole dose: $F(5,20)=3.49, p$ $=0.02]$. As can be seen in Figure 1 , quinpirole produced a complex dose/response curve in these animals: very low doses $(<0.01 \mathrm{mg} / \mathrm{kg})$ impaired performance, moderate doses $(0.01-0.1$ $\mathrm{mg} / \mathrm{kg}$ ) often improved performance, while the highest doses $(>0.1 \mathrm{mg} / \mathrm{kg})$ produced many side effects which often interfered with performance [polynomial contrasts $3^{\circ}: F(1,4)=10.63, p$ $=0.03]$.

A more intensive analysis of the impairment induced by very low quinpirole doses $(0.0001-0.005 \mathrm{mg} / \mathrm{kg})$ was performed to determine whether the pattern of errors was consistent with cognitive deficits (impairment at non " 0 " delays) or with nonspecific impairment (e.g., errors at " 0 " sec delays). Analysis of variance (2-ANOVA-R) with variables of drug [quinpirole (optimal dose) vs saline], and delay showed a significant effect of drug $[F(1,4)$ $=35.71, p=0.004]$, a significant effect of delay $[F(4,16)=$ $3.12, p<0.045$ ), and no significant drug by delay interaction $[F(4,16)=1.61, p=0.22]$. The absence of a drug by delay interaction appeared to result from floor effects at the longest delays, as an interaction emerged if the longest delays were removed from the analysis $[F(2,8)=3.76, p=0.07]$. Post hoc tests revealed that low dose quinpirole treatment significantly impaired performance following intermediate delays only $[F(1,4)=23.1, p=0.009\rfloor$. As delayed response impairment could be dissociated from drug-induced changes in sedation or fine motor performance (Table 1), this pattern was considered compatible with impaired PFC cognitive function.

Higher doses $(>0.01 \mathrm{mg} / \mathrm{kg})$ of quinpirole improved $(>27 / 30$ trials correct) the delayed response performance of four of five young adult monkeys (all but 613; see Fig. 1). Analysis of the pattern of improvement produced by the most efficacious dose of quinpirole indicated that beneficial effects were most evident following the longest delays [2-ANOVA-R with variables of quinpirole (optimal dose) and delay: significant effect of quinpirole- $F(1,4)=15.36, p=0.017$; post hoc tests: significant effect of quinpirole at longest delays- $F(1,4)=16.00, p=$ $0.016]$. Improvement was repeated in only three of five monkeys (443, 643, 666); thus, challenge with antagonists was limited to these animals (see below).

Young, reserpine-treated monkeys. To test for drug actions at pre- versus postsynaptic D2 receptors, the response to quinpirole was charactcrized in young monkeys chronically treated with reserpine to deplete endogenous catecholamines. If quinpirole remained effective in reserpine-treated monkeys, a postsynaptic site of action would be supported, while loss of efficacy would support a pre-synaptic site of action at DA autoreceptors. Al-

each individual animal in this experiment is indicated by the horizontal line; the range of matched saline performance for each individual animal in this experiment is indicated by the dashed horizontal lines. Sedation and agitation scores different from 0 are indicated; description of these scores is given in Materials and Methods. HLB indicates that an "hallucinatory-like" behavior was observed at that dosage during cognitive testing. 


\section{A. DELAYED RESPONSE AND SEDATION}

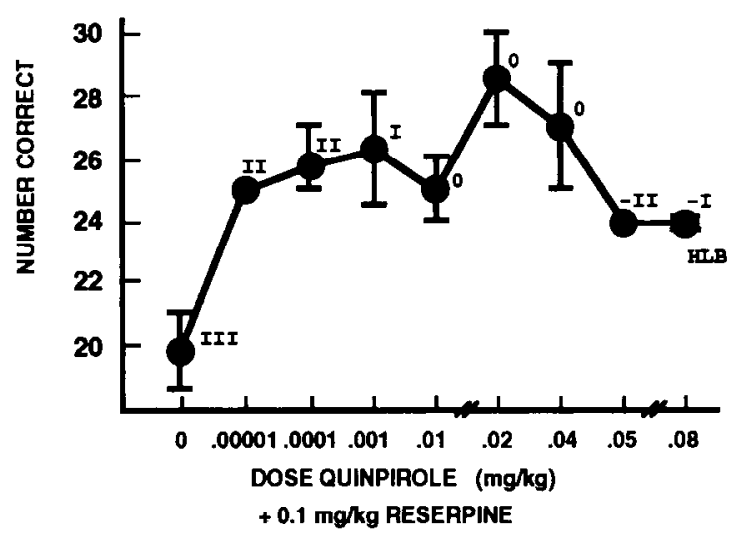

B. FINE MOTOR

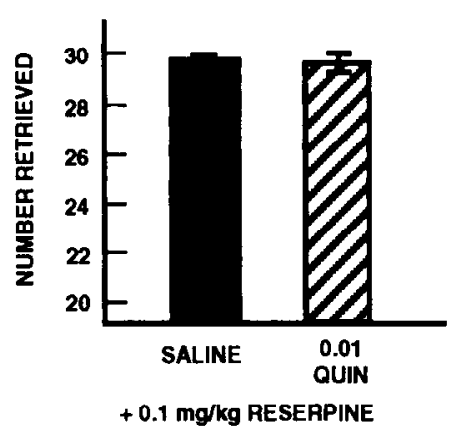

C. RESERPINE VS AGED: DELAYED RESPONSE

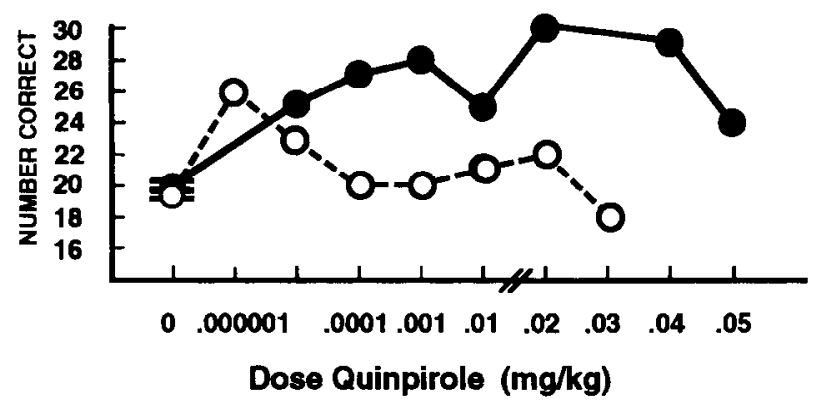

Figure 3. The effects of quinpirole in young monkeys $(n=3)$ chronically treated with the catecholamine-depleting agent, reserpine $(0.1 \mathrm{mg} /$ $\mathrm{kg}) . A$, The effects of quinpirole on delayed response performance and sedation in the reserpine-treated monkeys. Results represent mean trials correct \pm range of performance on the delayed response task, and median sedation scores (description of these scores is given in the Materials and Methods). Quinpirole significantly improved delayed response performance and alleviated sedation in the reserpine-treated monkeys. "Hallucinatory-like" behaviors (HLB) were evident following higher doses $(0.06-0.08 \mathrm{mg} / \mathrm{kg})$. $B$. The effects of quinpirole $(0.01 \mathrm{mg} / \mathrm{kg})$ on the mean \pm SEM number of rewards retrieved on the fine motor task during a $30 \mathrm{~min}$ time interval. Quinpirole did not induce fine motor impairment in reserpine-treated monkeys. $C$, Comparison of quinpirole's effects on delayed response performance in reserpine-treated young monkcy 8 (aged 9 ycars; solid circles) and aged monkey 343 (estimated age 33 years; open circles). Results represent the number correct out of a possible 30 trials. Mean \pm SEM saline performance is shown $(0 \mathrm{mg} /$ $\mathrm{kg}$ ). Note that the young, reserpine-treated monkeys and the aged monkeys have a similar level of baseline performance following saline treatment $(0 \mathrm{mg} / \mathrm{kg}$ quinpirole), yet quinpirole was more efficacious in the young, reserpine-treated monkeys.
Table 1. Quinpirole doses that impair delayed response versus fine motor performance

\begin{tabular}{llll} 
& \multicolumn{3}{l}{ Dose $(\mathrm{mg} / \mathrm{kg})$ that impairs performance of the: } \\
\cline { 2 - 4 } & $\begin{array}{l}\text { Delayed response } \\
\text { task }\end{array}$ & $\begin{array}{l}\text { Fine motor } \\
\text { task }\end{array}$ & $\begin{array}{l}\text { Sedation } \\
\text { score }^{\text {i }}\end{array}$ \\
\hline Monkey 442 & 0.0001 & 0.01 & I \\
Monkey 443 & 0.001 & 0.001 & 0 \\
Monkey 666 & 0.005 & 0.01 & I \\
Monkey 613 & 0.005 & 0.01 & I \\
Monkey 643 & 0.0001 & - & - III to 0.
\end{tabular}

"Sedation scores produced by dose of quinpirole that produced maximal impairment on the delayed response task.

though reserpine-treated monkeys exhibit deficits in delayed response performance (Cai et al., 1993), their baseline performance is approximately $70 \%$ correct (Fig. $3 \mathrm{~A}$ ), permitting room for either drug-induced impairment or improvement in performance. Results of this experiment showed that, in contrast to normal animals, reserpine-treated monkeys demonstrated a monophasic response to quinpirole (Fig. $3 A$ ). Both low and high doses of quinpirole produced a significant improvement in delayed response performance in these animals [1-ANOVA-R on quinpirole dose: $F(12,4)=18.85, p=0.009$ ]. Post-hoc analysis showed that even the lowest doses significantly improved performance $\lceil F(1,2)=111.73, p=0.009$ for the $0.0001 \mathrm{mg} / \mathrm{kg}$ dosage]. Drug-induced improvement in delayed response performance did not correlate significantly with changes in sedation scores (all $p$ values $>0.1$; Fig. $3 A$ ), indicating that improved delayed response scores were not due to simply to changes in arousal. The robust improvement in delayed response performance produced by quinpirole in reserpine-treated animals indicates that quinpirole's heneficial effects on cognitive performance result from actions at postsynaptic receptors. Conversely, the absence of delayed response deficits following low quinpirole doses in reserpine-treated animals suggests that the low dose impairment observed in young adult monkeys may result from actions at presynaptic autoreceptors.

Aged monkeys. As can be seen in Figure 2, the effects of quinpirole on delayed response performance weakened with increasing age. Two of the youngest aged animals (e.g., monkey 502, Fig. 2) still exhibited dose/response curves resembling those of young adult animals, but the amplitude of the impairment at low doses was less than that seen in young animals. Two other monkeys in this younger age group exhibited irregular dose/response curves, showing both impairment and improvement with quinpirole trcatment, but with no simple relationship to dose (e.g., monkey 499, Fig. 2). In these monkeys, quinpirole induced marked agitation (e.g.. sedation scores of -III), which may be responsible for their erratic responses. The four oldest aged animals exhibited simpler dose/response curves. Three of these animals had monophasic dose/response curves (e.g., monkey 343, Figs. 2, 3C; monkey 107, Fig. 2), exhibiting improvement at very low doses. This improvement disappeared at higher doses as hypotension disrupted performance. The fourth very old monkey showed a flat dose/response curve (monkey 121, Fig. 2), with delayed response impairment at high doses again being associated with hypotension and/or general behavioral disruption. It is noteworthy that a low dose of quinpirole induced behavioral quieting (sedation score of I) in aged monkey 121 , without evidence of delayed response impairment. The altered 
A.

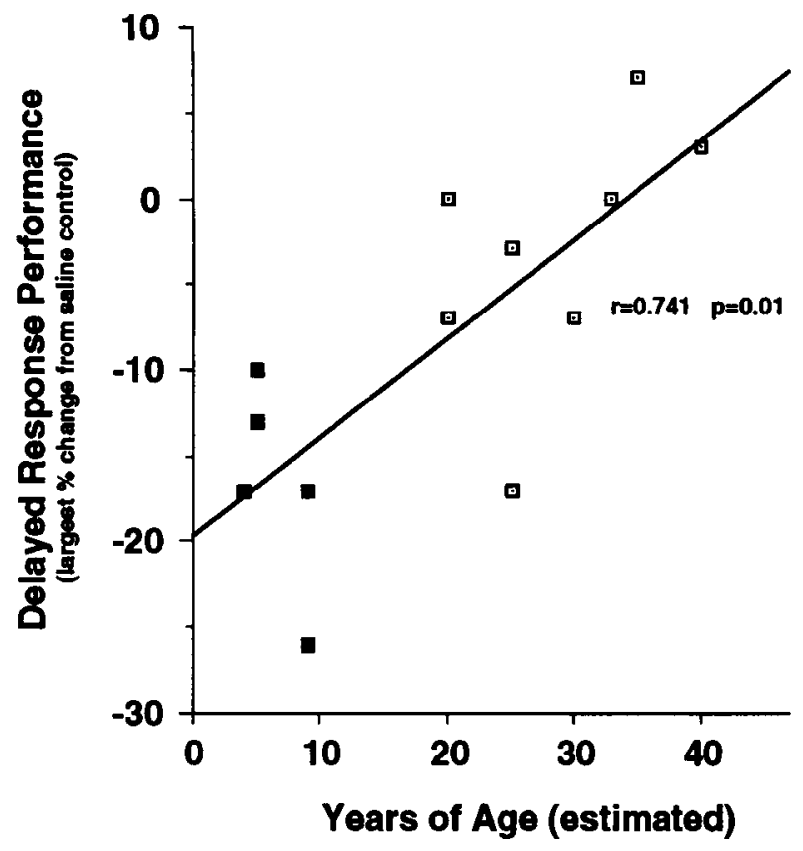

B.

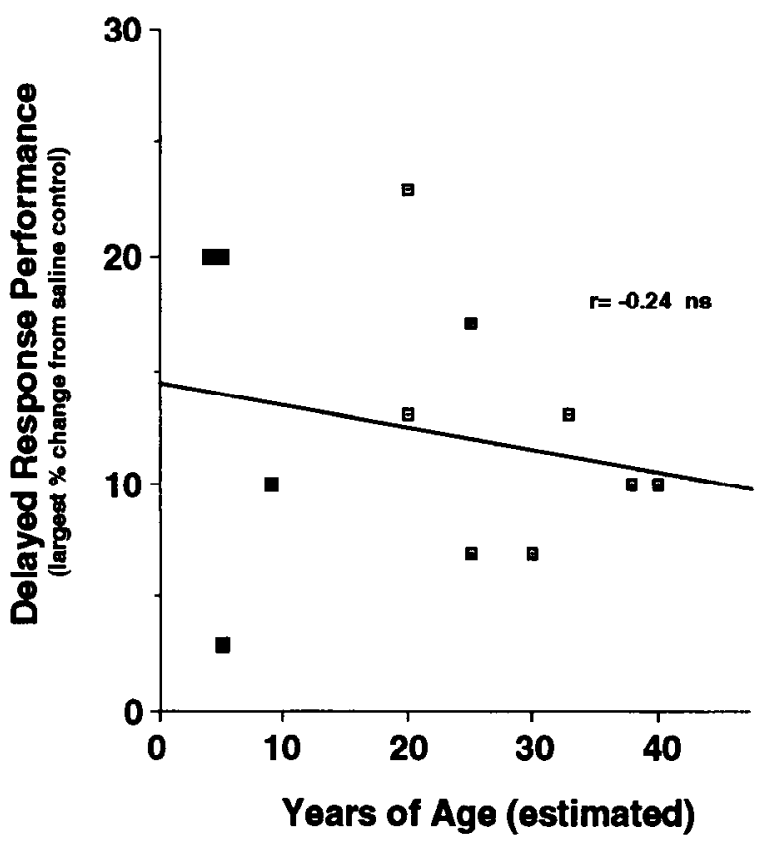

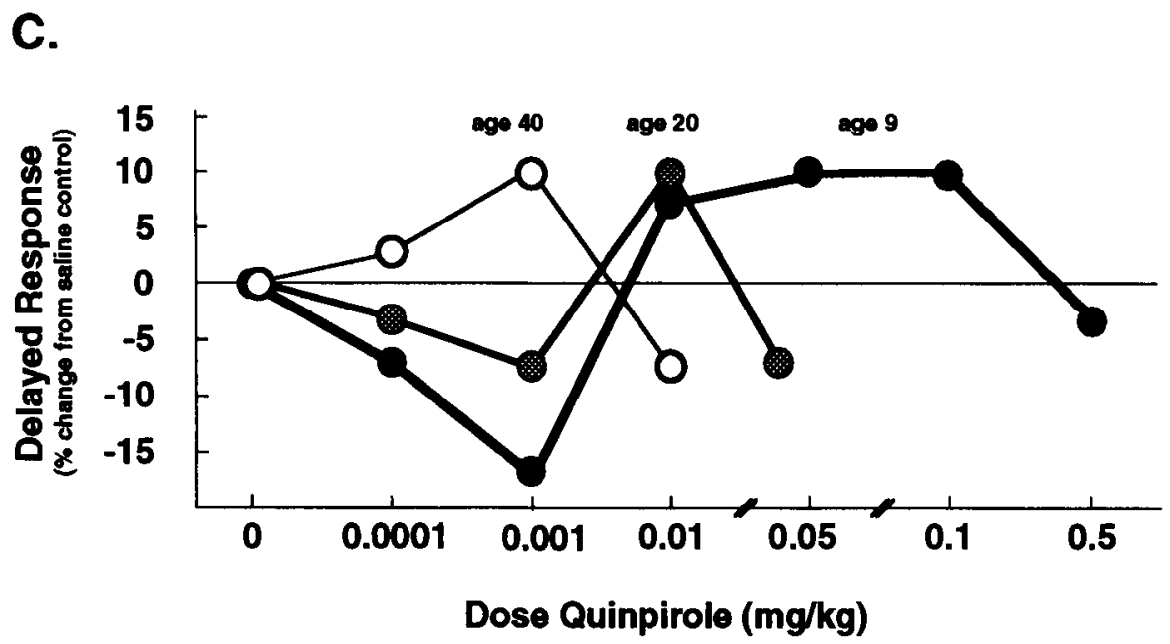

Figure 4. A, The correlation between estimated age and the efficacy of low doses of quinpirole $(<0.01 \mathrm{mg} / \mathrm{kg})$ to impair delayed response performance. Data from young monkeys are represented using solid squares; from aged monkeys using open squares. The impairment produced by low quinpirole doses diminished with advancing age (Spearman test: $r=0.746, n=13, p<0.01$ ). $B$, The correlation between estimated age and the efficacy of any dose of quinpirole to improve delayed response performance. The improvement produced by quinpirole tended to decrease with advancing age, but this relationship did not reach statistical significance (Spearman test: $r=-0.47, n=13, p<0.1$ ). $C$, Selected dose/ response curves illustrating age-related changes in the response to quinpirole. With advancing age, there was a (1) loss of low dose quinpiroleinduced impairment of delayed response performance, and (2) a leftward shift in doses capable of improving delayed response performance. Results represent percent change from saline control performance for monkeys 443 (est. age 9 years), 502 (est. age 20+ years), and 107 (est. age 40 years).

drug responses in the aged animals resulted in a nonsignificant overall effect of quinpirole [1-ANOVA-R: effect of quinpirole dose: $F(3,24)=0.155, p=0.925]$.

Inspection of the quinpirole dose/response curves in aged monkeys suggested that the low dose response was particularly altered in aged animals relative to young adults. Statistical comparison confirmed this observation: low doses $(<0.01 \mathrm{mg} / \mathrm{kg})$ of quinpirole produced significantly less impairment in the aged versus young adult monkeys (comparison of most efficacious dose in young vs aged monkeys: $t$-ind $=3.51, \mathrm{~d} \int=12, p=$ $0.004)$. Additional analysis revealed this to be a progressive change with advancing age: a significant inverse correlation was found between estimated age and the magnitude of the impairment produced by low doses of quinpirole (Spearman $r=0.746$, $p<0.01, n=14$; Fig. $4 A$ ). Figure $4 C$ illustrates this successive loss of quinpirole's efficacy to impair delayed response performance in three representative monkeys. The 9 year old monkey was impaired by quinpirole $(0.0001-0.001 \mathrm{mg} / \mathrm{kg})$, the 20 year 


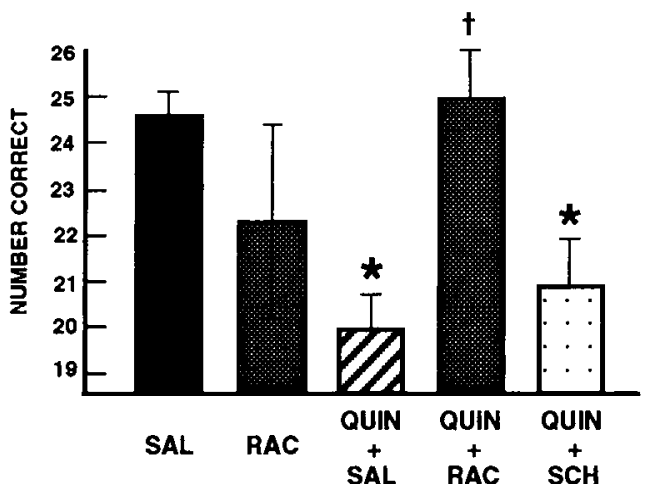

Figure 5. The efficacy of equimolar doses of D2 (raclopride) and D1 (SCH23390) antagonists in blocking the detrimental effects a low dose of quinpirole on delayed response performance in young monkeys $(n$ $=4$ ). Results represent mean \pm SEM number of trials correct. The low dose quinpirole response was significantly blocked by coadministration of raclopride, but not by $\mathrm{SCH} 23390$ ). SAL, saline; QUIN, quinpirole (most effective dose); RAC, raclopride $(0.001 \mathrm{mg} / \mathrm{kg}) ; \mathrm{SCH}, \mathrm{SCH} 23390$ $(0.00065 \mathrm{mg} / \mathrm{kg})$; *, significant difference from saline control performance; + , significant difference from quinpirole + saline.

old showed milder impairment, while the 40 year old animal was improved in this same dose range. These very old animals did not exhibit drug-induced impairment in delayed response performance even following extremely low doses $(0.000001-$ $0.00005 \mathrm{mg} / \mathrm{kg}$; e.g., Fig. 2, monkey 343). The change in response with advancing age was not simply an artifact of the aged animals performing at a lower baseline, as a significant inverse correlation was found between estimated age and the magnitude of the inpainnent produced by low doses of quinpirole for the aged monkeys by themselves (Spearman $r=0.79$, $p<0.05, n=8$ ).

Statistical analysis of the high dose $(>0.01 \mathrm{mg} / \mathrm{kg})$ quinpirole response also suggested a loss of beneficial drug effects with advancing age (Spearman test: $r=-0.637, n=13, p<0.02$ ). However, this relationship resulted in part from a leftward shift in the effective doses for the old animals below $0.01 \mathrm{mg} / \mathrm{kg}$. With increasing age, progressively lower doses were needed to improve performance above baseline performance (correlation between estimated age and most effective, beneficial dose of quinpirole in the aged monkeys: Spearman $r=-0.839, p=$ 0.05 ). This shift in potency is illustrated in Figure $4 C$, where the 9 year old animal was improved by higher quinpirole doses $(0.01-0.1 \mathrm{mg} / \mathrm{kg})$, the 20 year old animal by an intermediate dose, and the oldest animal by the lowest doses of quinpirole. When these lower doses were included in the correlative analysis, a loss of drug-induced improvement with advancing age was no longer apparent (Fig. 4B).

The quinpirole dose/response curves of several very old monkeys showed only improvement, resembling those of young, reserpine-treated monkeys, although of lesser magnitude. Both aged and reserpine-treated young monkeys had comparable levels of baseline performance (about 20/30 trials correct), but the mean optimal improvement observed in the reserpine-treated monkeys was $22.0 \% \pm 3.8 \%$ over baseline, while the mean optimal improvement for the aged monkeys was only $12.5 \% \pm$ $2.0 \%(t$-ind $=2.68, \mathrm{df}=9, p=0.025)$. A comparison between quinpirole's effects in a young, experimentally depleted monkey and aged monkey 343 can be seen in Figure $3 C$. Although quinpirole produced larger improvement in monkey 343 than in any other aged animal, it produced still greater improvement in the

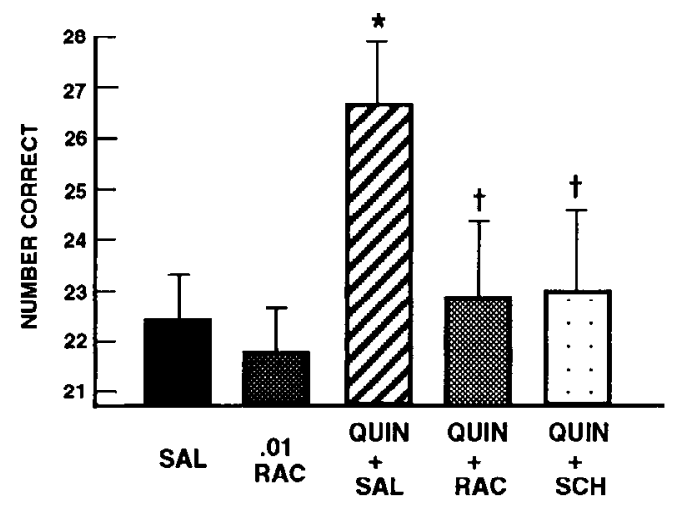

Figure 6. The efficacy of a D2 (raclopride) and D1 (SCH23390) antagonist in blocking the beneficial effects of quinpirole on delayed response performance in young and aged monkeys. Results represent mean \pm SEM number of trials correct. Higher doses of raclopride $(0.01-0.2 \mathrm{mg} / \mathrm{kg})$ were needed to block the beneficial effects of quinpirole treatment. $\mathrm{SCH} 23390(0.0065 \mathrm{mg} / \mathrm{kg})$ was also effective, suggesting an interaction hetween $\mathrm{D} 2$ and $\mathrm{D} 1$ receptors. $S A I$, Saline; QUIN, quinpirole (most effective dose); $R A C$, raclopride; $S C H$ SCH23390; * indicates significant difference from saline control performance.

young, reserpine-treated animals who were able to achieve perfect performance following an optimal dose of quinpirole. These findings suggest decreased postsynaptic D2 function in the aged monkeys.

Receptor mechanisms. To determine whether the impairment in delayed response performance produced by low doses of quinpirole in young adult monkeys resulted from actions at D2 receptors, the quinpirole response was challenged with either the D2 antagonist, raclopride, or the D1 antagonist, SCH23390. As can be seen in Figure 5, treatment with raclopride $(0.001 \mathrm{mg} /$ $\mathrm{kg}$ ) significantly reversed the impairment produced by a low dose of quinpirole (quinpirole doses listed in Table 1; quinpirole + saline vs quinpirole + raclopride: $t$-dep $=3.16, \mathrm{df}=3, p=$ 0.05 ). In contrast, an equimolar dose of the DI antagonist, SCH23390 $(0.00065 \mathrm{mg} / \mathrm{kg})$, did not reverse the impairment produced by quinpirole $(t$-dep $=1.09, \mathrm{df}=3, p=0.35)$. As these low doses of raclopride (Fig. 5) and SCH23390 (Arnsten et al., 1994) do not in themselves impair delayed response performance, the results indicate that the impairment produced by low doses of quinpirole is due largely to actions at $\mathrm{D} 2$ receptors.

The receptor mechanisms underlying the beneficial effects of quinpirole on delayed response performance were tested in both the young and aged monkeys in whom improvement was repeated (young monkeys: $n=3 / 5$, aged monkeys: $n=3 / 5$ ). The improvement in delayed response performance was blocked by the D2 antagonist, raclopride (Fig. 6; quinpirole + saline vs quinpirole + raclopride: $t$-dep $=6.76$, df $=5, p=0.001$ ). However, while the $0.001 \mathrm{mg} / \mathrm{kg}$ raclopride dose was sufficient to block the impairment produced by low quinpirole doses in young monkeys, higher doses of raclopride $(0.01-0.2 \mathrm{mIg} / \mathrm{kg})$ were needed to reverse quinpirole's beneficial effects. This was true even for the aged monkey who was improved by a very low dose of quinpirole $(0.00001 \mathrm{mg} / \mathrm{kg})$ : the $0.001 \mathrm{mg} / \mathrm{kg}$ dose of raclopride did not block the improvement, while the $0.01 \mathrm{mg} /$ $\mathrm{kg}$ raclopride dose was effective.

The beneficial effects of quinpirole were also challenged with a DI antagonist. Cotreatment with an equimolar dose of SCH23390 (e.g., $0.0065 \mathrm{mg} / \mathrm{kg}$ for those monkeys receiving 
$0.01 \mathrm{mg} / \mathrm{kg}$ raclopride) also significantly reversed the high-dose improvement by quinpirole (Fig. 6; quinpirole + saline vs quinpirole I SCH23390: $t$-dep $=4.39$, df $=5, p=0.007)$. Thus, the beneficial effects of quinpirole appear to involve interactions between D1 and D2 receptors. As quinpirole has very low affinity for DI receptors (Dearry et al., 1990), it is most likely that this interaction involves endogenous DA stimulation of D1 receptors, a result commonly found in rodent studies (White et al., 1988; Waddington, 1989).

\section{Quinpirole's effects on fine motor performance}

Young adult monkeys. Low doses $(0.0001-0.01 \mathrm{mg} / \mathrm{kg}$ ) of quinpirole produced significant impairment in the fine motor performance of young adult monkeys (Fig. $7 \mathrm{~B}$; saline vs. most effective dose quinpirole: $t$-dep $=7.56$, df $=3, p=0.005$ ). In contrast to delayed response performance, however, higher doses did not improve fine motor performance in most animals. It is noteworthy that the dose of quinpirole which impaired fine motor performance was higher than the dose necded to impair delayed response performance in all but monkey 443 (Table 1).

Young, reserpine-treated monkeys. The role of pre- vs postsynaptic drug actions was explored in monkeys chronically treated with reserpine. In order to minimize the bias of floor effects in these debilitated animals, the time allotted to perform the task was increased to restore previous levels of baseline performance (see Materials and Methods).

In contrast to normal monkeys, quinpirole did not impair reserpine-treated monkeys performing the fine motor task (Fig. $3 B$ ). Although $0.01 \mathrm{mg} / \mathrm{kg}$ quinpirole impaired most of the nonreserpine-treated monkeys, this dose had no effect in any reserpine-treated monkey. These results are consistent with a presynaptic mechanism underlying the detrimental effects of low quinpirole doses on fine motor performance.

Aged monkeys. Similar to previous results on the Rosette retrieval task (Bachevalier et al., 1991), fine motor performance was not impaired in the aged monkeys. Aged animals, like young monkeys, were able to retrieve large numbers of rewards $(>20 / 30 \mathrm{sec}$ ) following saline treatment (young vs. aged: $t$-ind $=0.29$, df $=7, p=0.78$; Fig. $7 A$ ). Although there were differences between animals in levels of baseline performance, there was little within subject variation. For example, the average SEM in performance for the aged animals was only \pm 1.5 rewards retrieved $( \pm 0.3)$. The consistency in saline performance allowed meaningful analysis of drug effects on fine motor function.

As with young, adult monkeys, low doses of quinpirole significantly impaired fine motor performance in the aged monkeys $(0.01 \mathrm{mg} / \mathrm{kg}$ quinpirole vs saline: $t$-dep $=3.67$, $\mathrm{df}=4, p=$ 0.02 ; Fig. $7 C$ ). There was no significant difference between quinpirole's efficacy in young vs aged monkeys (largest impairment seen in young monkeys: $-10.7 \pm 4.1$, in aged monkeys: $-8.4 \pm 1.3 ; t$-ind $=0.62$, NS).

Receptor mechanisms. To determine whether quinpirole's effect on fine motor performance involved actions at D2 receptors, the quinpirole response was challenged with the D2 antagonist, raclopride. Concomitant treatment with raclopride $(0.001-0.01$ $\mathrm{mg} / \mathrm{kg}$ ) significantly blocked the impairment produced by an optimal dose of quinpirole in both the young (quinpirole + saline vs quinpirole + raclopride: $t$-dep $=6.05, \mathrm{df}=2, p=0.026$ ), and aged monkeys $(0.001 \mathrm{mg} / \mathrm{kg}$ quinpirole + saline vs $0.001 \mathrm{mg} /$ $\mathrm{kg}$ quinpirole $+0.001 \mathrm{mg} / \mathrm{kg}$ raclopride $): t$-dep $=6.10, \mathrm{df}=2$, $p=0.026)$.

\section{FINE MOTOR PERFORMANCE}

A.

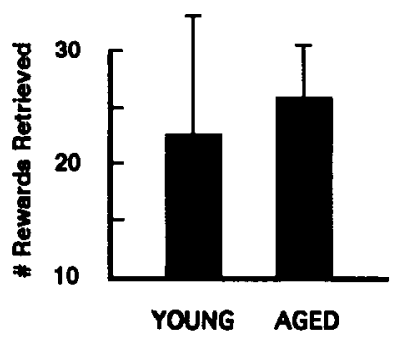

\section{B. Young Monkeys}

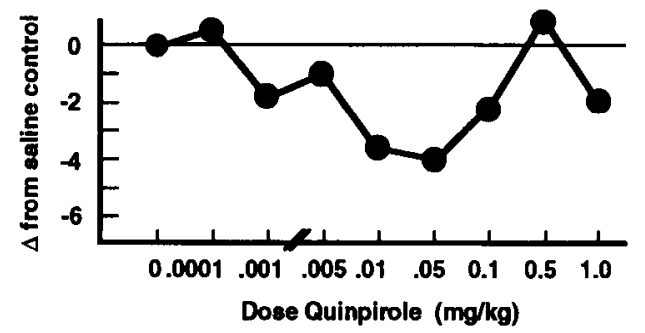

\section{Aged Monkeys}

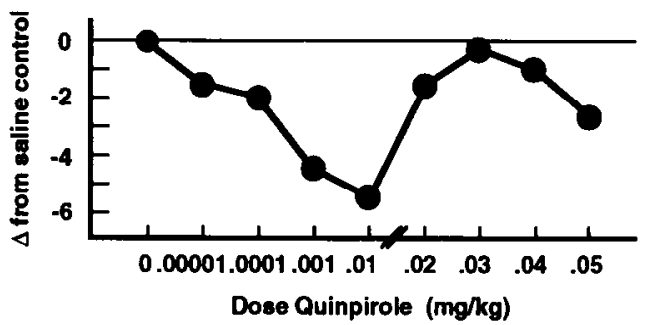

Figure 7. A, Aged $(n=5)$ and young $(n=4)$ monkcys showed comparable performance on the fine motor task following saline pretreatment. Results represent mean \pm SEM number of rewards retrieved in $30 \mathrm{sec}$. B. The effects of increasing doses of quinpirole on the fine motor performance of four young monkeys. Results represent the mean difference between performance on drug versus matched saline control (i.e., number retrieved quinpirole minus number retrieved saline). Low doses of quinpirole significantly impaired fine motor performance without general behavioral disruption. $C$, The effects of increasing doses of quinpirole on the fine motor performance of five aged monkeys. Results represent the mean difference between performance on drug versus matched saline control (i.e., number retrieved quinpirole minus number retrieved saline). As with young monkeys, low doses of quinpirole significantly impaired fine motor performance.

Summary. Figure 8 illustrates quinpirole's effects on fine motor versus delayed response performance in three representative aged monkeys compared to a representative young monkey. In the young monkey (top graph), low doses of quinpirole impaired both fine motor and delayed response performance, while in the aged monkeys (lower graphs), low doses of quinpirole markedly impaired fine motor performance without impairing delayed response performance. As fine motor testing followed delayed response testing, the lack of efficacy on delayed response performance in the aged monkeys cannot be explained by termination of the drug's activity. Thus, there was a clear dissociation in 


\section{DELAYED RESPONSE}
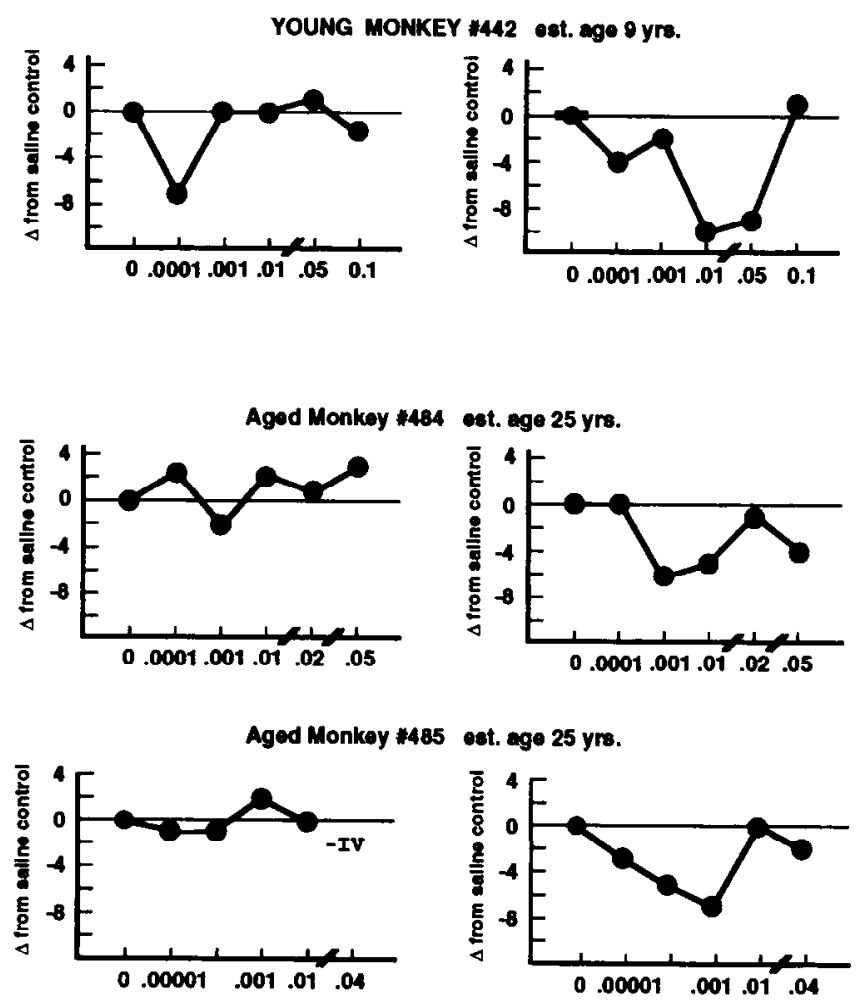

Aged Monkey *446 est. age 30 yrs.
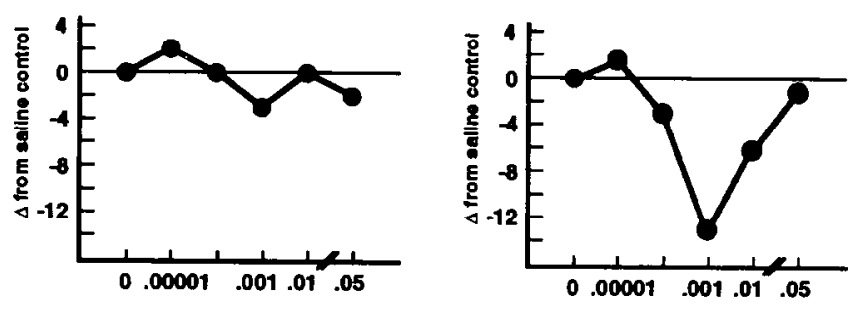

Dose Quinpirole (mg/kg)

Figure 8 . The effects of low doses of quinpirole on the delayed response versus fine motor performance of young monkey 442 and aged monkeys 484,485 , and 446 . Results represent differences in number of trials correct (delayed response) or number of rewards retrieved (fine motor) between drug and matched saline control. Low doses of quinpirole significantly impaired both delayed response and fine motor performance in young monkeys, but impaired only fine motor performance in aged monkeys. The score of -IV indicates too agitated to perform the delayed response task at this dose.

quinpirole's effects on delayed response vs fine motor performance in the young and aged monkeys.

\section{Discussion}

\section{Receptor mechanisms}

In young monkeys, low doses of quinpirole impaired delayed response and fine motor performance and produced behavioral quieting, while higher doses improved delayed response performance and produced a spectrum of behavioral changes including dyskinesias and "hallucinatory-like" behaviors. Data from reserpine-treated monkeys suggest that the changes produced by low doses of quinpirole resulted from actions at presynaptic D2 autoreceptors, while the responses produced by higher quinpi-

role doses resulted from drug actions at postsynaptic receptors. Although the reserpine model does not provide definitive support for this hypothesis, particularly given the debilitated state of these animals, the results are consistent with several other factors. For example, presynaptic drug actions agree with the shape of the dose/response curves in young monkeys: the impairment in delayed response and fine motor performance diminished with increasing dose. Quinpirole's affinity for D2 receptor subtypes is also in accordance with this hypothesis: quinpirole has highest affinity for the D3 site which has been localized both pre- and postsynaptically (Sokoloff et al., 1990), and slightly lower affinity for the D2 (ibid) and D4 subtypes (van Tol et al., 1991), the latter of which appears to be exclusively postsynaptic (ibid). The results of the raclopride challenge are similarly supportive. Raclopride has high affinity for the two subtypes which can be found presynaptically (D2 and D3; Sokoloff et al., 1990), and much lower affinity for the D4 subtype (van Tol et al., 1991). Low doses of raclopride were able to block the impairment in delayed response performance produced by low doses of quinpirole, while higher doses were needed to block the improvement produced by quinpirole. Higher raclopride doses were also needed to block the improvement produced by very low quinpirole doses in aged monkeys, indicating that the requirement for higher raclopride doses was not simply a mass action effect. These data suggest that low doses of quinpirole impair delayed response performance through actions at D2 or D3 autoreceptors, while the agonist may improve delayed response performance through actions at postsynaptic D4 receptors. The latter effect appears to involve an interaction with D1 receptors, as $\mathrm{SCH} 23390$ was also effective in blocking the beneficial effects of quinpirole on delayed response performance.

\section{Evidence for D2 influence on higher cortical function}

It is not known whether the low dose quinpirole response represents a true impairment in cognitive function, or a nonspecific change in performance. For example, D2 receptor mechanisms are known to play a powerful role in the functions of the nucleus accumbens and neostriatum, and thus it is very likely that quinpirole alters factors such as motivation (e.g., Taylor and Robbins, 1984; White et al., 1991; Beninger and Ranaldi, 1992) and motor responding (e.g., Barone et al., 1986), respectively. However, several lines of evidence support a direct effect of drug on cognitive functioning. First, delayed response impairment, fine motor impairment, and changes in sedation ratings occurred at different doses of quinpirole, indicating independent drug actions on these behaviors. Second, in aged monkeys, low doses of quinpirole impaired fine motor but not delayed response performance. These dissociations suggest that quinpirole impairs delayed response performance through direct effects on cognitive function, rather than indirect effects on performance variables which would produce a more unitary profile of impairment.

This pattern of deficits similarly implicates changes in cortical rather than striatal function. Disruption of striatal mechanisms might be expected to effect both the delayed response and fine motor tasks concurrently. Furthermore, monkeys with striatal dopamine depletion performing the delayed response task exhibit a qualitatively distinct pattern of impairment from that exhibited by quinpirole-treated monkeys: striatal dopamine depletion results in errors of omission on the delayed response task (Schneider, 1992), while low doses of quinpirole impair accuracy without altering the number of trials completed (current study). Given the relatively low levels of dopamine in the cortex 
compared to the striatum, the cortex may be more sensitive to the inhibitory effects of very low doses of quinpirole.

Previous research has suggested that D2 mechanisms do not underlie DA's beneficial effects on PFC cognitive functioning (Sawaguchi and Goldman-Rakic, 1991); however, this conclusion was based solely on results with raclopride, an antagonist with little D4 activity (van Tol et al., 1991). The current results of delayed response improvement following quinpirole treatment suggests that the D2 family of receptors, as well as the D1/D5 sites, may influence higher cognitive function. Stronger support for this hypothesis will require characterizing quinpirole's effects on the performance of tasks with the same motor needs as delayed response, but varying cognitive demands.

\section{Relevance to aging}

In contrast to young monkeys who exhibited impairment on both the delayed response and fine motor tasks following low doses of quinpirole, aged monkeys were impaired on the fine motor but not the delayed response task (e.g., Fig. 8). Doses as low as $0.000001 \mathrm{mg} / \mathrm{kg}$ were examined, but evidence of drug-induced impairment on the delayed response task was only seen in the youngest aged animals. These negative effects with quinpirole cannot be explained by floor effects, because low doses of clonidine were able to significantly impair many of these same aged monkeys using the identical delayed response paradigm (Arnsten et al., 1988). A more likely explanation is that the change in quinpirole's effects in the aged animals resulted from the heterogeneous pattern of DA loss in cortex. DA depletion is more pronounced in the PFC than the motor cortex of aged monkeys (Goldman-Rakic and Brown, 1981), a finding which may underlie the pronounced delayed response deficits and preserved fine motor function in these animals. Low doses of quinpirole may impair fine motor performance by inhibiting DA release in motor cortex through actions at D2 autoreceptors. Comparable drug actions at D2 autoreceptors in the DA-depleted PFC might have little effect on DA release, and thus produce no further impairment in the delayed response performance of aged monkeys. The highly significant correlation between the estimated age of a monkey and the ability of low quinpirole doses to impair delayed response performance is consistent with increasing loss of DA from the PFC with advancing age. Wenk et al. reported a drop in frontal pole DA levels from a mean of $1.8 \mathrm{ng} /$ $\mathrm{mg}$ at 7-9 years, to a mean of $0.5 \mathrm{ng} / \mathrm{mg}$ at $21-23$ years, to a mean of $0.1 \mathrm{ng} / \mathrm{mg}$ at $31-37$ years (numbers estimated from Fig. 2 of Wenk et al., 1989). The current data provide functional evidence for progressive DA depletion in the PFC with advancing age. The exceptional vulnerability of the PFC DA system should not be unexpected, given the increased sensitivity of these cells to stress and pharmacological treatment in rodent biochemical studies (Deutch and Roth, 1990).

In contrast to quinpirole's adverse effects on delayed response performance at low doses, its ability to improve delayed response performance remained relatively stable with advancing age. Five aged monkeys showed quinpirole-induced improvement which was blocked by raclopride, consistent with drug actions at D2 receptors. In three of the oldest animals, improvement shifted from the high dose to the low dose $(<0.01 \mathrm{mg} / \mathrm{kg})$ range, resembling the dose/response curves of young monkeys experimentally depleted of catecholamines with chronic reserpine treatment. However, there was evidence of decreased postsynaptic efficacy as well: the improvement seen in aged monkeys was of lesser magnitude than that seen in reserpine-treated young animals, and one of the oldest monkeys (121) did not show improvement following any dose of quinpirole. D2 receptor loss with age has been reported in the monkey and human striatum (e.g. Wong et al., 1984; Lai et al., 1987; Rinne et al., 1990), but has never been studied in the cortex where receptor numbers are much lower (Lidow et al., 1991).

There was also an age-related decline in the potency of quinpirole in inducing "hallucinatory-like" behaviors. Hallucinations are common side effects of D2 agonist (e.g., bromocriptinc) and L-dopa treatment of Parkinson's discase (Physician's Desk Reference), and thus the finding of "hallucinatory-like" behaviors in monkeys in the current study should not be unexpected. Furthermore, the decreased response with increasing age is consistent with the time course of positive symptoms in schizophrenia: hallucinations are most common during postadolescence and decrease with advancing age (Bleuler, 1968; Ciompi, 1980; Harding et al., 1987; Winokur et al., 1987). The presence of these abnormal behaviors in an animal model represents a unique opportunity to examine the neural mechanisms underlying an important clinical phenomenon.

\section{Additional evidence supporting a role for DA loss in age-related cognitive decline}

Previous studies of aged rats and monkeys affirm that loss of DA contributes to PFC cognitive deficits in aged individuals. Aged rats exhibit a marked loss of DA and its metabolites from the PFC, and this depletion correlates with age-related spatial working memory deficits better than any other biochemical measure (Luine et al., 1990). With advancing age, monkeys no longer exhibit PFC cognitive impairment when treated with a D1 antagonist, but do show improvement when treated with a D1 partial agonist, findings consistent with endogenous DA depletion in the PFC (Amsten et al., 1994). Aged humans also develop marked PFC cognitive deficits (e.g., Hochanadel and Kaplan, 1984; Davis et al., 1990) and pronounced decreases in PFC blood flow (Kuhl et al., 1984; Riege et al., 1985; Waldemar et al., 1991). Although the very low levels of DA in the cortex have as yet precluded an accurate biochemical analysis of DA levels from human postmortem tissue, the studies of aged animals suggest that DA depletion in the PFC may provide a major contribution to age-related cognitive decline.

\section{References}

Arnsten AFT, Cai JX, Goldman-Rakic PS (1988) The alpha-2 adrenergic agonist guanfacine improves memory in aged monkeys without sedative or hypotensive side effects. J Neurosci 8:4287-4298.

Arnsten AFT, Cai JX, Murphy BL, Goldman-Rakic PS (1994) Dopamine $\mathrm{D} 1$ receptor mechanisms in the cognitive performance of young adult and aged monkeys. Psychopharmacology 116:143-151.

Bachevalier J, Landis LS, Walker LC, Brickson M, Mishkin M, Price DL, Cork LC (1991) Aged monkeys exhibit behavioral deficits indicative of widespread cerebral dysfunction. Neurobiol Aging 12:99111.

Barone P, Davis TA, Braun AR, Chase TN (1986) Dopaminergic mechanisms and motor function: characterization of D1 and D2 receptor interactions. Eur J Pharmacol 123:109-114.

Bartus RT (1979) Effects of aging on visual memory, sensory processing and discrimination learning in a nonhuman primate. In: Sensory systems and communication in the elderly. Aging, Vol 10 (Ordy JM, Brizzee K, eds), pp 85-114. New York: Raven.

Bartus RT, Fleming D, Johnson HR (1978) Aging in the rhesus monkey: Debilitating effects on short-term memory. J Gerontol 33:858871 .

Beninger RJ, Ranaldi R (1992) The effects of amphetamine, apomorphine, SKF 38393, quinpirole and bromocriptine on responding for conditioned reward in rats. Behav Pharmacol 3:155-163. 
Bleuler M (1968) A 23-year longitudinal study of 208 schizophrenics and impressions in regard to the nature of schizophrenia. In: The transmission of schizophrenia (Rosenthal D, Kety SS, eds), pp 3-12. New York: Pergamon.

Brozoski T, Brown RM, Rosvold HE, Goldman PS (1979) Cognitive deficit caused by regional depletion of dopamine in prefrontal cortex of thesus monkey. Science 205:929-931.

Cai JX, Ma Y, Xu L, Hu X (1993) Reserpine impairs spatial working memory performance in monkeys: reversal by the alpha-2 adrenergic agonist clonidine. Brain Res 614:191-196.

Ciompi L (1980) Catamnestic long-term study on the course of life and aging of schizophrenics. Schizophr Bull 6:606-618.

Davis HP, Cohen A, Gandy M, Colombo P, Van Dusseldorp G, Simolke N, Romano J (1990) Lexical priming deficits as a function of age. Behav Neurosci 104:286-295.

Dearry A, Gingrich JA, Falardeau P, Fremeau RT Jr, Bates MD, Caron MG (1990) Molecular cloning and expression of the gene for a human D1 dopamine receptor. Nature 347:72-76.

Deutch AY, Roth RH (1990) The determinants of stress-induced activation of the prefrontal cortical dopamine system. Prog Brain Res 85:367-403.

Goldman-Rakic PS (1987) Circuitry of the primate prefrontal cortex and the regulation of behavior by representational memory. In: Handbook of physiology, the nervous system, higher functions of the brain, Sect 1, Vol V, Pt 1 (Plum F, ed), pp 373-417. Bethesda, MD: American Physiological Society.

Goldman-Rakic PS, Brown RM (1981) Regional changes of monoamines in cerebral cortex and subcortical structures of aging rhesus monkeys. Neurosci 6:177-187

Harding CM, Brooks GW, Ashikaga T, Strauss JS, Breier A (1987) The Vermont longitudinal study of persons with severe mental illness. II. Long-term outcome of subjects who retrospectively met DSM-III criteria for schizophrenia. Am J Psychiatry 144:727-735.

Hochanadel G, Kaplan E (1984) Neuropsychology of normal aging. In: Clinical neurology of aging (Albert ML, ed), pp 231-244. New York: Oxford UP.

Kuhl DE, Metter EJ, Riege WH, Hawkins RA (1984) The effect of normal aging on patterns of local cerebral glucose utilization. Ann Neurol [Suppl] 15:S133-S137.

Lidow MS, Goldman-Rakic PS, Gallagher DW, Rakic P (1991) Distribution of dopaminergic receptors in the primate cerebral cortex: quantitative autoradiographic analysis using $\left[{ }^{3} \mathrm{H}\right]$ raclopride, $\left[{ }^{3} \mathrm{H}\right]$ spiperone and $\left[{ }^{3} \mathrm{H}\right] \mathrm{SCH} 23390$. Neuroscience 40:657-671.

Nielsen EB, Lyon M, Ellison G (1983) Apparent hallucinations in monkeys during around-the-clock amphetamine for seven to fourteen days. J Nerv Ment Dis 171:222-233.

Lai H, Bowden DM, Horita A (1987) Age-related decreases in dopamine receptors in the caudate nucleus and putamen of the rhesus monkey (Macaca mulatta). Neurobiol Aging 8:45-49.

Lapin BA, Krilova RI, Cherkovich GM, Asanov NS (1979) Observations from Sukhumi. In: Aging in nonhuman primates (Bowden DM, ed), pp 14-37. New York: van Nostrand Reinhold.

Lewis DA, Campbell MJ, Foote SL, Goldstein M, Morrison JH (1987) The distribution of tyrosine hydroxylase-immunoreactive fibers in primate neocortex is widespread but regionally specific. J Neurosci 7:279-290.

Luine V, Bowling D, Hearns M (1990) Spatial memory deficits in aged rats: contributions of monoaminergic systems. Brain Res 537:271278.

Nielsen EB, Lyon M, Ellison G (1983) Apparent hallucinations in monkeys during around-the-clock amphetamine for seven to fourteen days. J Nerv Ment Disease 171:222-233.

Plantje JF, Steinbush HWM, Schipper J, Dijcks FA, Verheijden PFHM, Stoof JC (1987) D-2 dopamine-receptors regulate the release of $\left[{ }^{3} \mathrm{H}\right]$ dopamine in rat cortical regions showing dopamine immunoreactive fibers. Neuroscience 20:157-168.

Rapp PR, Amaral DG (1989) Evidence for task-dependent memory dysfunction in the aged monkey. $J$ Neurosci 9:3568-3576.

Riege WH, Metter EJ, Kuhl DE, Phelps ME (1985) Brain glucose metabolism and memory functions: age decrease in factor scores. $J$ Gerontol 40:459-467.
Rinne JO, I onnberg P, Marjamaki P (1990) Age-dependent decline in human brain dopamine D1 and D2 receptors. Brain Res 508:349352.

Sawaguchi T, Goldman-Rakic PS (1991) D1 dopamine receptors in prefrontal cortex: involvement in working memory. Science 251:947950.

Schneider JS (1992) Behavioral and neuropalhological consequences of chronic exposure to low doses of the dopaminergic neurotoxin MPTP. In: The vulnerable brain and environmental risks, Vol 2, Toxins in food (Isaacson RL, Jensen KF, eds), pp 293-308. New York: Plenum.

Sesack SR, Bunney BS (1989) Pharmacological characterization of the receptor mediating electrophysiological response to dopamine in the rat medial prefrontal cortex: a microiontophoretic study. J Pharmacol Exp Ther 248:1323-1333

Sokoloff P, Giros B, Martres M-P, Bouthenet M-L, Schwartz J-C (1990) Molecular cloning and characterization of a novel dopamine receptor (D3) as a target for neuroleptics. Nature 347:146 151.

Stroessner-Johnson HM, Rapp PR, Amaral DG (1992) Cholinergic cell loss and hypertrophy in the medial septal nucleus of the behaviorally characterized aged rhesus monkey. J Neurosci 12:1936-1944.

Taylor JR, Robbins TW (1984) Enhanced behavioral control by conditioned reinforcers following microinjections of $d$-amphetamine into the nucleus accumbens. Psychopharmacology 84:405-412.

Thierry AM, Le Douarin C, Penit J, Ferron A, Glowinski J (1986) Variation in the ability of neuroleptics to block the inhibitory influence of dopaminergic neurons on the activity of cells in the rat prefrontal cortex. Brain Res Bull 16:155-160.

Tigges J, Gordon TP, McClure HM, Hall EC, Peters A (1988) Survival rate and lifespan of rhesus monkeys at the Yerkes Regional Primate Research Center. Am J Primatol 15:263-273.

van Tol HM, Bunzow JR, Guan H-C, Sunahara RK, Seeman P, Niznik HB, Civelli O (1991) Cloning of the gene for the human dopamine D4 receptor with high affinity for the antipsychotic clozapine. Nature 350:610-614.

Voytko ML, Olton DS, Richardson RT, Gorman LK, Tobin JR, Price DL (1994) Basal forebrain lesion in monkeys disrupt attention but not learning and memory. $\mathrm{J}$ Neurosci 14:167-186.

Waddington JL (1989) Functional interactions between D-1 and D2 dopamine receptor systems: their role in the regulation of psychomotor behavior, putative mechanisms, and clinical relevance. J Psychopharmacol 3:54-63.

Waldemar G, Hasselbalch SG, Andersen AR, Delecluse F, Petersen P, Johnsen A, Paulson OB (1991) ${ }^{49 m} \mathrm{Tc}-d, l$-HMPAO and SPECT of the brain in normal aging. J Cereb Blood Flow Metab 11:508-521.

Walker IC, Kitt CA, Struble RG, Wagster MV, Price DL, Cork LC (1988) The neural basis of memory decline in aged monkeys. Neurobiol Aging 9:657-666.

Wenk GL, Pierce DJ, Struble RG, Price DL, Cork LC (1989) Agerelated changes in multiple neurotransmitter systems in the monkey brain. Neurobiol Aging 10:11-19.

Wenk GL, Walker LC, Price DL, Cork LC (1991) Loss of NMDA, but not GABA-A, binding in the brains of aged rats and monkeys. Neurobiol Aging 12:93-98.

White FJ, Bednarz LM, Wachtel SR, Hjorth S, Brooderson RJ (1988) Is stimulation of both $\mathrm{D} 1$ and $\mathrm{D} 2$ receptors necessary for the expression of dopamine-mediated behaviors? Pharmacol Biochem Behav 30:189-193.

White NM, Packard MG, Hiroi N (1991) Place conditioning with dopamine D1 and D2 agonists injected peripherally or into nucleus accumbens. Psychopharmacology 103:271-276.

Williams SM, Goldman-Rakic PS (1993) Characterization of the dopaminergic innervation of the primate frontal cortex using a dopamine-specific antibody. Cereb Cortex 3:199-222.

Winokur G, Pfohl B, Tsuang M (1987) A 40 year follow-up of hebephrenic-catatonic schizophrenia. In: Schizophrenia and aging (Miller $\mathrm{N}$, Cohen G, eds) pp 52-60. New York: Guilford.

Wong DF, Wagner HNJ, Dannals RF, LinksJM, Frost JJ, Ravert HT, Wilson AA, Rosenbaum AE, Gjedde A, Douglass KII, Petronis JD, Folstein MF, Toung JKT, Burns HD, Kuhar MJ (1984) Effects of age on dopamine and serotonin receptors measured by positron tomography in the living human brain. Science 226:1393-1396. 